\title{
Relações entre avós e seus netos adolescentes: uma revisão integrativa
}

\author{
Relationships between grandparents and their teenage grandchildren: an integrative review
}

\section{Resumo}

O objetivo do estudo foi analisar a relação entre avós e seus netos adolescentes, e descrever suas diferentes representações no cotidiano de seus netos por meio de revisão integrativa. Realizou-se a busca de artigos e resumos publicados no período de janeiro 2002 a junho de 2012, nas bases de dados LILACS e MEDLINE, por meio dos seguintes descritores: avós, netos adolescentes, relações entre avós e netos. Seguindo as estratégias definidas para o estudo, a busca resultou em seis artigos na íntegra. Foram incluídos dois artigos da base de dados LILACS e quatro da MEDLINE. Concluiu-se que as relações entre avós e netos adolescentes se diferenciaram de acordo com a proximidade entre os sujeitos, sendo esta derivada de diversos fatores, como corresidência, trabalho e estado civil dos netos, opções sexuais GLBT, origem e doenças crônicas dos avós. Pesquisas futuras que estudem essa temática são importantes para contribuir com um melhor entendimento da relação entre avós e seus netos na perspectiva de ambos os sujeitos.

\section{Abstract}

This study aimed to analyze the relationship between grandparents and their teenage grandchildren, and describe different representations in everyday of their grandchildren through an integrative review. A search for articles and abstracts published from January 2002 to June 2012, was conducted in MEDLINE and LILACS databases using the following descriptors: grandparents, grandchildren teenagers, relationships between grandparents and grandchildren. Following the strategies defined for the study, the search resulted in six full articles. Two articles from LILACS and four from MEDLINE were included. The conclusion was that the relationship between grandparents and teenage grandchildren differed according to the proximity of the subject, which is derived from several factors such as co-residence, work and marital status of the grandchildren, GLBT sexual choices, and chronic source of grandparents. Future research work assessing this issue are important to contribute to a better understanding of the relationship between grandparents and grandchildren from the perspective of both subjects.

\footnotetext{
Programa de Pós-graduação em Ciências e Tecnologias em Saúde, Faculdade de Ceilândia. Universidade de Brasília. Ceilândia, DF, Brasil.
}

Correspondência / Correspondence Alessandra Ribeiro Ventura Oliveira E-mail: a.oliveira53@gmail.com

Palavras-chave: Família. Relações Familiares. Adolescentes. Avós. Netos. Relacionamento entre avós e seus netos.

Key words: Family. Family Relations. Adolescent. Grandparents. Grandchildren. Relationship between grandparents and their grandchildren. 


\section{INTRODUÇÃO}

Estudos sobre a importância da relação entre avós e netos na literatura mundial vêm aumentando desde os anos 1980, como reflexo das alterações nas composições familiares, em que as pessoas vivenciam por mais tempo o papel de avô ou avó. ${ }^{1}$ De acordo com Redler, ${ }^{2}$ avosidade não remete a uma idade cronológica, mas a laço de parentesco localizado nas filiações trigeracionais, do ponto de vista pessoal, familiar e social. A arte de ser avós pode ser vista como um aspecto privilegiado da arte de ser pais de filhos adultos, de partilhar ideias e experiências dentro da nova condição de simetria que os filhos atingem ao se tornarem pais. ${ }^{3}$ Nesse momento, os avós precisam redefinir a nova posição que irão ocupar entre as gerações e devem alterar a representação de seu filho e desenvolver novos vínculos com o neto. ${ }^{4}$

As mudanças nas relações entre avós e netos decorrentes das transformações pelas quais as famílias vêm passando têm levado a um crescente questionamento sobre o papel dos avós na educação de seus netos. Em estudo realizado por Neugarten, em 1964, entrevistando 70 avós de classe média, foram estabelecidos cinco estilos diferentes de avós: divertidos, formais, distantes, cuidadores e conservadores da sabedoria familiar. ${ }^{5}$ Em 1976, foram descritos quatro estilos de exercer avosidade, que variam ao longo da vida e diferem de acordo com cada neto: permissivo, simbólico, individualista e tirano. ${ }^{6}$ Em outra classificação, em 1985, os estilos de avós foram divididos em três grupos: avós companheiros, avós tiranos e avós invólucros. ${ }^{7}$ Também em 1985, os avós foram classificados em quatros grupos: estar aí, guardião nacional da família, árbitro e conservador da biografia da família. ${ }^{8} \mathrm{O}$ conceito de estilo de avós vai além das práticas dos avós propriamente ditas. O estilo é, na verdade, o contexto dentro do qual operam os esforços dos avós em socializar seus netos, de acordo com suas crenças e valores.

De acordo com Aratangy \& Posternak, ${ }^{3}$ o século XXI será o século dos avós. Na população dos Estados Unidos, cerca de 50\% tornam-se avós entre 49 e 53 anos. Na França, cerca de 80\% das avós têm mais de 65 anos e $50 \%$ destas se tornarão bisavós. ${ }^{3} \mathrm{Na}$ Inglaterra, quase metade da população tem netos, e cerca de $25 \%$ destes são os principais cuidadores dessas crianças, passando em média seis horas por semana substituindo os pais. $^{2}$ Em estudo realizado por Oliveira, concluiu-se que a frequência de contato com o neto passou a ser fator importante nos efeitos positivos dessa relação. ${ }^{10}$

Os avós atuais assumem papéis multidimensionais, tanto na sociedade quanto na família. Até então, foram demonstrados conceitos estabelecidos para os estilos de avós por meio de níveis: nível de atitude, nível de conduta, nível emocional ou afetivo e nível simbólico. ${ }^{11}$ De acordo com Dias \& Silva, ${ }^{12}$ o relacionamento avós-netos marcado pelo prazer e brincadeiras ocorre mais na infância, mas à medida que os netos vão crescendo, outros significados vão adquirindo mais relevância, como as características dos próprios avós e seus netos, assim como da relação.

A adolescência é considerada, dentre aqueles que a caracterizam de forma universal, uma etapa de transição entre a infância e a idade adulta, tendo como base as transformações puberais, de caráter biológico, que desencadeiam mudanças psicológicas e sociais até atingir a maturidade. ${ }^{13}$ Essa etapa do desenvolvimento humano corresponde, para a maioria daqueles que integram essa tendência, à segunda década da vida, ou seja, dos dez aos 20 anos, sendo considerados adolescentes todos aqueles que se situarem no referido grupo etário. ${ }^{13}$

Para compreender as relações entre avós e seus netos adolescentes, há necessidade de maior aprofundamento sobre o tema, pois nessa etapa da vida ocorrem transformações físicas, psíquicas e sociais. O presente estudo propôs-se a realizar uma revisão integrativa, que é um método de revisão amplo. ${ }^{14,15} \mathrm{O}$ objetivo da pesquisa foi realizar uma revisão integrativa sobre avós e seus netos adolescentes, descrevendo as diferentes relações entre ambos, em que os avós passam a desempenhar funções multidimensionais na família e na sociedade atuais. 


\section{MATERIAIS E MÉTODOS}

\section{Estratégias de busca}

Estudo realizado por meio de levantamento bibliográfico nas bases de dados: Literatura Latino-Americana e do Caribe em Ciências da Saúde (LILACS) e Medical Literature Analysis and Retrieval Sistem on-line (MEDLINE). Foram utilizados, como critérios de busca dos artigos, os seguintes descritores e suas combinações nas línguas portuguesa, inglesa e espanhola: avós, netos adolescentes, relações entre avós e seus netos; grandparents and grandchildren relationships, grandparents and teenager grandchildren; relaciones abuelos y nietos, abuelos y nietos adolescientes. Foram identificados 24 artigos na MEDLINE e quatro na LILACS, totalizando 28. Os critérios de inclusão foram: artigos publicados em português, inglês e espanhol; artigos na íntegra que retratassem a temática das diferentes relações entre avós com idade acima de 50 anos e seus netos adolescentes, publicados no período de 2002 a 2012.

\section{Análise e descrição dos artigos}

Foram avaliados títulos e resumos dos 28 artigos identificados, com vistas à inclusão entre os que seriam lidos na íntegra. O critério de inclusão para leitura na íntegra foi a existência de qualquer referência às relações entre avós e netos adolescentes. Foram selecionados 16 artigos para serem lidos integralmente, mas dez foram excluídos, sendo quatro por não ter sido possível o acesso ao texto na íntegra e seis por não atenderem aos critérios de inclusão estabelecidos para a pesquisa. O estudo foi então realizado com seis artigos, estabelecendo-se entre as avaliadoras que, na existência de alguma discordância quanto à seleção do artigo, este seria analisado por um terceiro revisor, profissional de área afim ao tema do estudo.

A análise e síntese dos dados obtidos foram realizadas de forma descritiva, possibilitando observar, descrever e classificar os dados, com o intuito de reunir o conhecimento produzido sobre o tema avosidade e netos adolescentes. Para a extração dos dados dos artigos selecionados, utilizou-se um instrumento previamente elaborado e adaptado por Ursi, ${ }^{16}$ em 2005, capaz de assegurar que a totalidade dos dados relevantes fosse extraída, que o risco de erros na transcrição dos dados fosse mínimo e que houvesse precisão na checagem das informações. Os dados incluíram: definição dos sujeitos, metodologia, tamanho da amostra, mensuração de variáveis, método de análise e conceitos embasadores empregados. $\mathrm{O}$ anexo 1 representa o instrumento utilizado. ${ }^{16} \mathrm{~A}$ organização das informações dos artigos foi realizada por meio de uma síntese das principais informações de cada estudo em uma tabela contendo os seguintes tópicos: procedência, título do artigo, autores, periódico, considerações e temática. 
Anexo 1. Instrumento para coleta de dados (Ursi). ${ }^{16}$

\begin{tabular}{|c|c|}
\hline A- Identificação & \\
\hline Título do artigo & \\
\hline Título do periódico & \\
\hline Autores & Nome \\
\hline País & Local de trabalho \\
\hline Idioma & Graduação \\
\hline Ano de publicação & \\
\hline B- Instituição sede do artigo & \\
\hline Hospital & \\
\hline Universidade & \\
\hline Centro de pesquisa & \\
\hline Instituição única & \\
\hline Pesquisa multicêntrica & \\
\hline Outras instituições & \\
\hline Não identifica o local & \\
\hline C- Tipo de publicação & \\
\hline Publicação de enfermagem & \\
\hline Publicação médica & \\
\hline Publicação de outra área da saúde. Qual? & \\
\hline
\end{tabular}

1. Tipo de publicação

Pesquisa ( ) abordagem quantitativa - delineamento

( ) experimental

( ) quase experimental

( ) não experimental

( ) abordagem qualitativa

Não-pesquisa

( ) revisão de literatura

( ) relato de experiência

( ) outras

2. Objetivo ou questão de investigação 


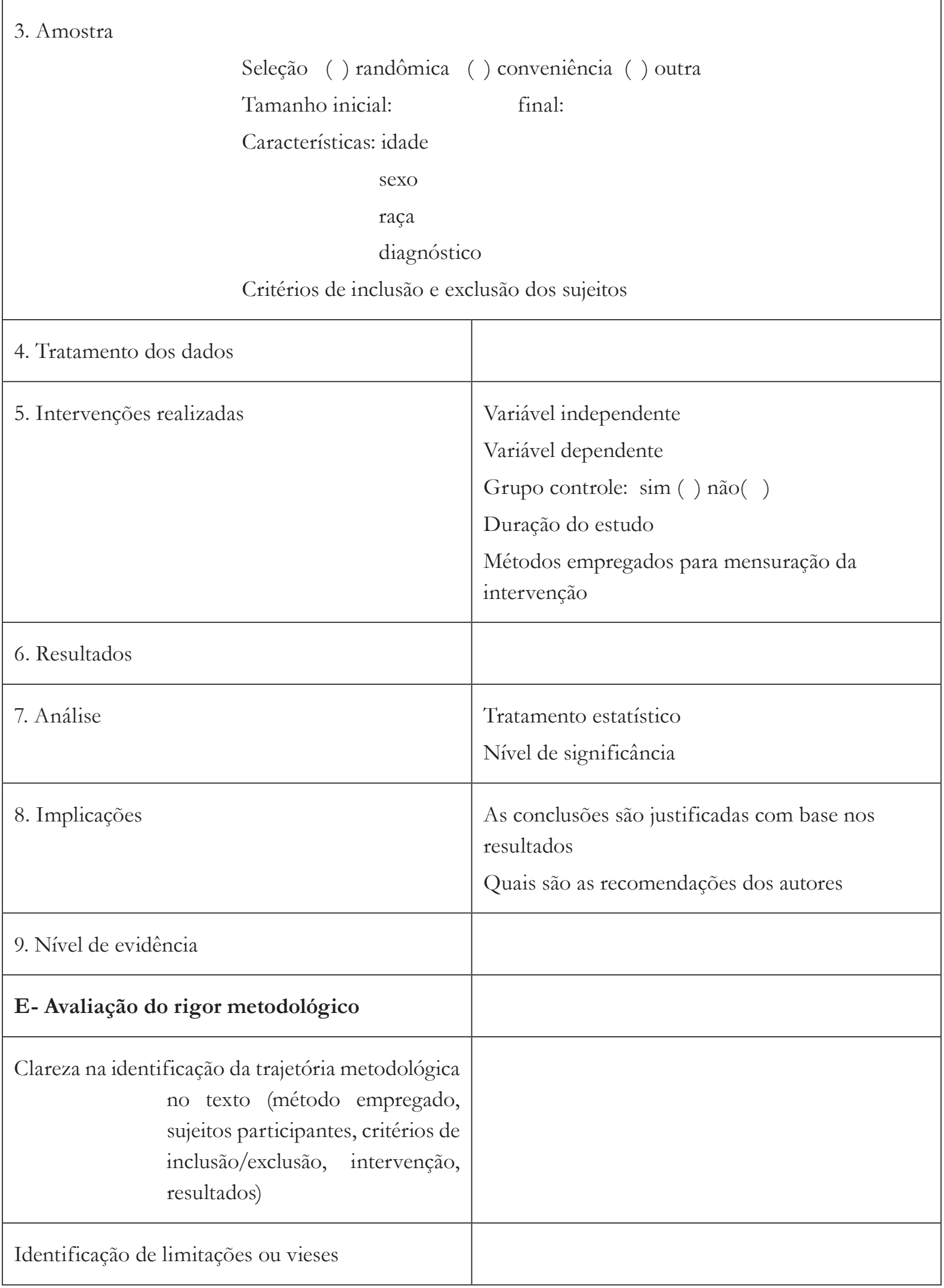




\section{RESULTADOS E DISCUSSÃO}

Ao avaliar os seis artigos incluídos no estudo sobre relações entre avós e seus netos adolescentes, verificou-se que a maioria aborda relações sob a perspectiva de ambos os sujeitos. ${ }^{17-21} \mathrm{~A}$ análise sob a perspectiva dos netos tornou-se mais frequente a partir de $2000 .^{12,22}$

De acordo com os resultados da análise multivariada realizada no primeiro estudo chinês que examina sistematicamente prevalência, intensidade e determinantes de avós que cuidam de netos na China contemporânea, apesar da crescente disponibilidade das creches, os avós continuam a servir como importantes cuidadores infantis alternativos. ${ }^{18}$ A disponibilidade de ajuda das avós contribui para que as mães, principalmente, tenham maior tempo para buscar retorno financeiro por meio do trabalho fora do lar. Esse tipo de arranjo familiar corresponde aos encontrados em outros estudos de famílias que fazem parte de economias em transição, como a da China contemporânea. ${ }^{18-20}$ Os autores concluem que os cuidados dos avós com seus netos infantes e adolescentes é uma expressão de continuidade cultural e, ao mesmo tempo, uma demonstração da flexibilidade dos vínculos familiares. ${ }^{18}$

No estudo de Monserud, ${ }^{19}$ realizado por meio de entrevistas com adolescentes e adultos divididos em dois grupos (10 a 18 anos e de 18 a 23 anos), mostrou-se por meio de estatística descritiva que as relações de netos adolescentes com seus avós eram mais propensas a se deteriorarem com a diminuição da proximidade entre eles, sobretudo quando os netos passavam a trabalhar em tempo integral. Em estudo transversal, foi demonstrado que netos adultos que viviam em sua própria casa apresentavam diminuição quanto ao tempo de contato com os avós. ${ }^{17}$ As preocupações e responsabilidades assumidas pelos netos adolescentes e adultos ao se tornarem independentes financeira e residencialmente podem ter como consequência a menor frequência de contato com os avós. Os resultados indicaram também que netos casados apresentavam maior contato com seus avós maternos. Observou-se, ainda, que a transição dos netos ao casamento parece aumentar o tempo de contato com avós paternos. ${ }^{19}$

Os avós têm sido membros ignorados das famílias nas pesquisas a respeito de relações familiares gays, lésbicas, bissexuais, transexuais, travestis e transgêneros (GLBT). ${ }^{20} \mathrm{O}$ estudo de Scherrer sugere que avós possam ser capazes de aceitar seus netos GLBT, mas ainda não foi realizado estudo que possa confirmar tais dados. ${ }^{20}$

O estudo de Taylor \& Washington, ${ }^{21}$ em 2007, foi a primeira tentativa de desenvolver uma base de conhecimento sobre a influência das atitudes parentais sobre a pressão arterial quando os avós estão cuidando dos netos, porém foram considerados apenas avós afro-americanos. Os resultados mostrando maior disposição e bom humor na realização das atividades diárias ${ }^{21}$ podem estar relacionados a fatores socioculturais dos avós participantes do estudo.

No estudo realizado por Araújo \& Dias, ${ }^{22}$ apenas duas das avós possuíam netos adolescentes. A avó que residia com o neto cuidava dele desde o nascimento, pois a mãe não tinha condições de criá-lo, motivo não detalhado pelo estudo. A outra avó residia com os netos adolescentes durante os cinco dias da semana, pois no fim de semana eles iam para a casa dos pais. As avós relataram sentimento de esperança promovido pelos desafios de cuidar dos netos e um sentido para a própria existência. ${ }^{22}$ Os avós não eram idosos, pois todos tinham idades abaixo de 58 anos, o que mostra, de acordo com os autores, que não é possível associar os avós apenas à imagem de pessoas idosas. O estudo apresentou pequeno número de participantes, com diferentes características das relações entre avós e netos, pois havia netos de diversas idades. ${ }^{22}$

No estudo de Falcão \& Bucher-Maluschke, ${ }^{23}$ em 2009, com avós portadoras de doença de Alzheimer, no período anterior à instalação da doença afirmou-se que havia bom relacionamento intergeracional para alguns, o 
que facilitou o papel de cuidadoras pelas filhas e netas. Já no período após a doença, verificou-se que não houve diferença significativa na relação entre avós e netos. Observou-se que netos que tinham maior proximidade geográfica das avós exerciam mais ações solidárias e cuidadosas. ${ }^{23}$ Em cerca de $60 \%$ dos estudos ${ }^{23,24}$ sobre a doença de Alzheimer nas relações intergeracionais, o fator socioeconômico contribuiu para o menor tempo de contato entre avós e seus netos. $\mathrm{O}$ autor observou que nas representações atuais, a coesão das cuidadoras com seus filhos foi significativamente maior do que a coesão destes com suas avós, e que a maioria dos filhos das respondentes tinha maior proximidade afetiva com os avós portadores de doença de Alzheimer. ${ }^{23}$ De acordo com a literatura, ${ }^{24} \mathrm{o}$ aumento no número de famílias monoparentais, além de vários membros trabalharem fora do lar, limitou o número de pessoas disponíveis para exercerem as tarefas de cuidado em casa. Com isso, crianças e adolescentes foram levadas a assistirem ou assumirem os cuidados de adultos com doenças degenerativas que moram na mesma residência. ${ }^{25}$

Quadro 1. Artigos levantados nas bases de dados LILACS e MEDLINE sobre relações entre avós e seus netos adolescentes, no período de 2002 a 2012

$\begin{array}{ll}\text { Procedência } & \text { MEDLINE } \\ \text { Título } & \text { Intergerational ties in context: grandparents caring for grandchildren in China } \\ \text { Autores } & \text { Chen F, Liu G, Mair C A. } \\ \text { Periódico } & \text { Soc Forces. } 90 \text { (2): 571-594, dec 2011. } \\ \text { Temática } & \text { Os resultados sugerem que a guarda das crianças por avós ajusta-se às necessidades } \\ & \text { da família; no entanto, ao mesmo tempo é reflexo do clima cultural atual na China. } \\ & \text { A guarda das crianças é restringida pelas necessidades dos pais de trabalharem fora } \\ \text { de casa. A norma patriarcal ainda pode estar presente, mas com a ajuda dos avós, as } \\ \text { decisões relativas às atividades dos netos tornam-se mais discutidas. A importância } \\ \text { dos avós como substitutos potenciais no acolhimento aos netos se dá especialmente } \\ \text { quando a carga de atividades das mães se torna mais exigente. } \\ \text { Procedência } & \text { MEDLINE } \\ \text { Autores } & \text { Changes in grandchildren's adult role statuses and their relationships with grandparents } \\ \text { Periódico } & \text { Monserud M A. } \\ \text { Temática } & \text { J Fam Issues. 32(4):425-451,Apr 2011. } \\ & \begin{array}{l}\text { Observou-se que netos que deixam a casa dos pais podem estar menos disponíveis } \\ \text { para seus avós maternos em momentos de necessidade. Netos adultos que não }\end{array} \\ & \text { frequentam faculdade podem ter mais oportunidades para fortalecer suas relações com } \\ & \text { seus avós. Empregos em tempo integral parecem desviar a atenção dos netos de seus } \\ \text { relacionamentos com seus avós. Netos casados experimentam maior contato com seus } \\ \text { avós maternos ao longo do tempo. Observou-se também que os netos solteiros têm } \\ \text { mais tempo e disposição para se dedicarem aos seus avós maternos. Netos divorciados } \\ \text { de ambos os sexos mostraram-se mais próximos de seus avós maternos. Os netos } \\ \text { únicos apresentaram maior proximidade de seus avós. }\end{array}$




\begin{tabular}{|c|c|}
\hline Procedência & MEDLINE \\
\hline Título & The intergenerational family relationships of grandparents and GLBQ grandchildren \\
\hline Autores & Scherrer K S \\
\hline Periódico & J GLBT Fam Stud 6 (3): 229-269, Jul 2010. \\
\hline Temática & $\begin{array}{l}\text { Trata-se de uma revisão empírica inglesa e indica que os avós, a partir da convivência } \\
\text { com um neto sabidamente GBLT, podem apresentar reações de amor e de apoio a seu } \\
\text { neto. Observou-se que o papel dos avós pode estar negligenciado nos estudos atuais. } \\
\text { Os avós podem ser a única fonte de apoio de seus netos GBLT. Estima-se que para } \\
\text { os netos gays, } 15 \% \text { das avós e } 8 \% \text { dos avôs têm conhecimento de suas preferências } \\
\text { sexuais. }\end{array}$ \\
\hline Procedência & MEDLINE \\
\hline Título & Urban hypertensive African American grandparents: stress, health and implications of child care \\
\hline Autores & Taylor J Y, Washington O G, \\
\hline Periódico & Clin Gerontol. 2007 Jun 1; 30(4): 39-54 \\
\hline Temática & $\begin{array}{l}\text { O estudo concluiu que os avós mais jovens passavam mais tempo cuidando de seus } \\
\text { netos do que os avós mais velhos. Bom humor e maior disposição para a realização de } \\
\text { suas atividades diárias foram os efeitos na saúde de avós mais jovens relacionados com } \\
\text { a prestação de cuidados a seus netos. }\end{array}$ \\
\hline Procedência & LILACS \\
\hline Título & Avós guardiões de baixa renda \\
\hline Autores & Araújo, C P, Dias, C M . \\
\hline Periódico & Pesquisas e Práticas Psicossociais 4(2): 229-237, Jul.2010. \\
\hline Temática & $\begin{array}{l}\text { O estudo concluiu que os principais motivos que levaram os avós a criarem seus netos } \\
\text { foram a gravidez na adolescência por parte de um filho e sua separação. A iniciativa de } \\
\text { criar seus netos partiu geralmente dos avós e os sentimentos experimentados por eles } \\
\text { foram de satisfação e felicidade. O estudo concluiu também que a criação dos netos } \\
\text { deve continuar com os próprios avós. }\end{array}$ \\
\hline Procedência & LILACS \\
\hline Titulo & O impacto da doença de Alzheimer nas relações intergeracionais \\
\hline Autores & Falcão, D V; Bucher-Maluschke J S. \\
\hline Periódico & Psic. Clin.,21(1): 137-152, 2009. \\
\hline Temática & $\begin{array}{l}\text { Através da análise de conteúdo, observou-se que alguns netos sentiam prazer em } \\
\text { realizar atividades com as avós antes do aparecimento da doença de Alzheimer. Já outros } \\
\text { netos não aprovavam a maneira de agir das avós com os mesmos. Após a instalação } \\
\text { da doença, alguns netos passaram a ajudar a cuidar das avós, enquanto outros netos } \\
\text { relataram agressividade por parte das avós, o que dificultou o cuidado com as mesmas. } \\
\text { Observou-se também que nas representações atuais das relações intergeracionais, a } \\
\text { união das filhas cuidadoras com seus filhos foi significativamente maior do que a } \\
\text { união dos netos com as avós portadoras da doença de Alzheimer. }\end{array}$ \\
\hline
\end{tabular}


A relação entre avós e netos ainda é tema pouco estudado. Os avós, cada vez mais, estão ocupando novos papéis com as mudanças que estão ocorrendo nas famílias. Nesta pesquisa, alguns fatores que determinam a configuração dessa relação não foram explorados: diferenciação quanto ao sexo tanto dos avós quanto dos netos, número de netos para cada avô ou avó, idade dos avós, a história de relacionamento com os filhos e seus parceiros e determinações culturais.

Reconhecem-se então, algumas limitações, como a de considerar avós independentemente da variável gênero, quando se sabe que esta também possui grande importância. Entretanto, devido a pouca quantidade de respondentes do sexo masculino, sua análise não foi possível como desejado, o que certamente poderia ter enriquecido a pesquisa. Não se destacou se o neto é filho único, o que implicaria, provavelmente, maior atenção dos avós, situação que favorece maior contato. Os resultados encontrados nos estudos analisados não permitiram uma divisão por faixa etária quanto aos netos, diante da amplitude do período da adolescência, o que certamente enriqueceria também o estudo.

\section{REFERÊNCIAS}

1. Dias CMSB, Silva DV. Os avós: uma revisão da literatura nas três últimas décadas. In: Féres-Carneiro T, organizadora. Casal e família, entre a tradição e a transformação. Rio de Janeiro: Ed. Nau; 1999, p. 118-149.

2. Redler P. Abuelidade. Más Allá de La Paternidade. Argentina: Ed. Legasa; 1986.

3. Aratangy LR, Posternak L. Livro dos avós: na casa dos avós é sempre domingo? São Paulo: Artmeios; 2005. $175 \mathrm{p}$.

4. Kipper CDR; Lopes RS. O tornar-se avó no processo de individuação. Psic.: Teor. e Pesq [online] 2006;22(1):29-34.

5. Neugarten BL, Weinstein KK. The changing american grandparent. Journal of Marriage and Family 1964;26(1):199-204.

6. Roberto KA, Stroes J. Grandchildren and grandparents: roles, influences and relatioships. Int J Anging Hum Dev 1992;34(3):227-39.
Essas variáveis, entretanto, constituirão objeto de futuras pesquisas.

\section{CONSIDERAÇÕES FINAIS}

Neste estudo, observou-se que as relações entre avós e netos adolescentes se diferenciaram de acordo com a proximidade entre os sujeitos, sendo esta derivada de diversos fatores como: corresidência, trabalho dos netos em tempo integral, netos pertencentes às características GLBT, idade e presença de doenças crônicas dos avós.

Reuniram-se resultados de pesquisas sobre diferentes tipos de relações entre avós e seus netos adolescentes, de maneira sistemática e ordenada, mas ainda com um pequeno número de estudos. Desse modo, pesquisas futuras com o objetivo de analisar as relações entre avós e seus netos adolescentes precisam ser realizadas, para um melhor entendimento do tema e sob a perspectiva de ambos os sujeitos. Com o aumento da expectativa de vida, o tempo de vivência no papel de avós tem se tornado maior e os estilos de avós provavelmente se diferenciarão mais, sobretudo em relação aos netos adolescentes.
7. Cherlin AJ, Furstenberg FF. Styles and strategies of grandparenting. In: Bengtson VL, Robertson JF, editors. Grandparenthood. Beverly Hills, CA: Sage Publications; 1985. p. 97-116.

8. Bengtson VL, Robertson JF, editores. Grandparenthood. Beverly Hill, CA: Sage Publications; 1985.

9. Darling N, Steinberg L. Parenting style as a context: an integrative model. Psychological Bulletin 1993;113(3):487-96.

10. Oliveira ARV, Vianna LG, Cárdenas CJ. Avosidade: visões de avós e de seus netos no período da infância. Rev Bras Geriatr Gerontol 2010;13(3):461-74.

11. Osuna MJ. Relaciones familiares en la vejez: vínculos de los abuelos y de las abuelas con sus nietos y nietas en la infancia. Rev Multidiscip Gerontol 2006;16(1):16-25.

12. Dias CMSB, Silva MAS. Os avós na perspectiva de jovens universitários. Psicol Estud 2003;8(n.esp):55-62. 
13. Peres F, Rosenburg CP. Desvelando a concepção de adolescência/adolescente presente no discurso da saúde pública. Saúde e Soc 1998;7(1):53-86.

14. Broome ME. Integrative literature reviews for the development of concepts. In: Rodgers BL, Knafl KA, editors. Concept development in nursing: foundations, thecniques and applications. Philadelphia (USA): W.B Saunders Company; 2000. p. 231-50.

15. Polit DF, Beck CT. Using research in evidence-based nursing practice. In: Polit DF, Beck CT, editors.

Essentials of nursing research. Methods, appraisal and utilization. Philadelphia (USA): Lippinncott Willians \& Wilkins; 2006. p. 457-94.

16. Ursi ES. Prevenção de lesões de pele no perioperatório: revisão integrativa da literatura [dissertação].

Ribeirão Preto: Universidade de São Paulo, Escola de Enfermagem de Ribeirão Preto; 2005.

17. Mazutti C, Scortegagna HM. Velhice e envelhecimento humano: concepções de pré-escolares do município de Tapejara-RS. RBCEH 2006;3(2):101-12.

18. Chen F, Liu G, Mair CA. Intergerational Ties in Context: grandparents caring for grandchildren in China. Soc Forces 2011;90(2):571-94.
19. Monserud MA. Changes in granchildren's adult role statuses and their relationships with grandparents. J Fam Issues 2011;32(4):425-51.

20. Scherrer KS. The intergerational family relationships of grandparents and GLBQ grandchildren. J GLBT Fam Stud 2010;6(3):229-64.

21. Taylor JY, Washington OG, Artinian NT, Lichtenberg P. Urban hypertensive African American grandparents: stress, health and implications of child care. Clin Gerontol 2007;30(4):39-54.

22. Araújo CP, Dias CMSB. Avós guardiões de baixa renda. Pesqui Prát Psicossociais 2010;4(2):229-37.

23. Falcão DVS, Bucher-Maluschke JSNF. O impacto da doença de Alzheimer nas relações intergeracionais. Psicol Clin 2009;21(1):137-52.

24. Biegel DE, Schulz R. Caregiving and caregiver interventions in aging and mental illness. Family Relations 1999;48(4):345-54.

25. Lackey NR, Gates MF. Adults' recollections of their experiences as young caregivers of family members with chronic physical illnesses. J Adv Nurs 2001;34(3):320-8. 